\title{
Evaluating long-term potential evapotranspiration and soil moisture dynamics at Shanghai City China
}

\author{
Manqi Wang \\ Shanghai Jianping High School
}

\begin{abstract}
As the finical hub of China, the Shanghai metropolitan area is one of the most important regions on earth, which requires significant efforts in water, energy and resources management and supply. Ongoing dynamic changes in climate have posed large uncertainties in our ability to better quantify, estimate and predict future hydrological and ecological responses, including soil moisture dynamics and potential evapotranspirative demands. Given these significant implications, in this study, we focused on better understanding long-term dynamic trends in soil moisture and potential evapotranspiration at Shanghai with the Hargreaves equation and 1-Dimensional flow transport with Richard's equation. We further tested how perturbations in temperature and precipitation patterns influence soil moisture and potential evapotranspiration responses. Our results suggested significant correlation between temperature and potential evapotranspiration as well as precipitation inputs and soil moisture. We believe these results can provide useful insights to help us better understand the hydrological responses at Shanghai to climate change.
\end{abstract}

\section{Introduction}

As an important link between the energy and water cycle, evapotranspiration (ET) represents the key process to transfer water and energy from the land surface back to the atmosphere. ET contributes to more than $15 \%$ of the total atmospheric water vapor [1]. Without ET, ecosystem dynamics will be significantly altered leading to uncertain effects over the atmosphere-biosphere-hydrosphere compartments, including precipitation, cloud formation, soil moisture, temperature and vegetation dynamics [2-4]. Thus, quantifying ET dynamics is particularly important to better understand how ecosystem respond to gradual and abrupt changes in the climate, which is also extremely important for the socioeconomic and societal benefits in our civilization.

Understanding ET dynamics is also important for water and energy management in Shanghai, which is the financial hub of China that contributed to $\$ 553$ billion Gross Domestic Production (GDP). Urban development and population growth have caused significant changes in the land topography, leading to tremendous fluctuations in hydrology cycles, including soil moisture, vegetation loss, floods, and droughts [5-6]. Recent gradual climate changes can further increase the occurrences of extreme events (e.g., droughts and floods) as well as intensify the environmental risks [7]. Thus better understanding ET dynamics at Shanghai can help us better develop water and energy resources management plans to improve the sustainability of urban ecosystem.

Numerous methods have been used to estimate ET in various environmental conditions. Ground-based approaches, such as eddy covariance tower and flux chambers, have been applied to directly measure carbon and water fluxes [8]. Analytical and semi-analytical solutions have been developed to quantify ET, including the Penman-Monteith equation, the Priestley-Taylor equation and their extensions. Physically-based approaches focus on solving the energy and water balances equations and numerically represent ET through differential equations, such as the Community Land Model. Remote-sensing methods have also been used to provide proxies for ET at numerous locations. For example, Zou et al. [9] measured ET and quantify the cooling effects of urban hedges through the development of "three temperature model and infrared remote sensing". Ma et al. [10] estimate ET with only meteorological variables to investigate the spatiotemporal variations of ET in the data-scarce region of the Tibetan Plateau. However most of these studies require datasets that are difficult to obtain, and very few of them focus on the Shanghai region. Thus there's still a need to provide estimates of ET to quantify how climate change and urban development change ET dynamics in the past decades.

In this study, we used the Hargreaves equation [11] to estimate evapotranspiration at a Shanghai weather station, which only requires minimum data including minimum and maximum daily air temperature and precipitation; and also Richard's equation to quantify soil moisture dynamics at the subsurface, which provide us information for flooding and droughts. With these estimation, we were able to quantify inter- and intra-annual variability of ET and soil moisture at Shanghai, which can be beneficial for future water and energy resources management. The remainder of this study is as follows: section presents the materials and methods used in this study. Section 3 mainly 
presents the results with discussion and conclusions in section 4.

\section{Materials and methods}

\subsection{Site and meteorological data}

As the financial hub of China, Shanghai locates in the alluvial plain of the Yangtze River Delta, and have experienced fast economic growth and development as well as urbanization. Shanghai has a latitude of $30^{\circ} 40^{\prime} n-31^{\circ} 53^{\prime} \mathrm{N}$ and longitude of $120^{\circ} 52^{\prime} \mathrm{E}-$ $122^{\circ} 12^{\prime} E$, covering an area of over $6340 \mathrm{~km}^{2}$. The average rainfall is approximately $1200 \mathrm{~mm}$, whereas more than $60 \%$ of the annual rainfall occur during summer periods.

We obtained meteorological data that include daily minimum and maximum air temperature data and precipitation data from rain gauge station $\mathrm{CH} 00058362$ $\left(31.40^{\circ} \mathrm{N}, 121.49^{\circ} \mathrm{E}\right)$, which locates in the Baoshan district of the Shanghai municipal area. These data ranges from 1991 to 2012, which enabled us to capture long-term temporal variability in meteorological conditions as well as providing input datasets for us to quantify temporal variability of potential evapotranspiration and subsurface soil moisture dynamics.

Here you can refer to Liang 2017 and Jiang 2017 paper and see how they discuss the site information.

\subsection{Estimating potential evapotranspiration with the Hargraves equation}

In this study, we applied the Hargraves equation [11] to estimate potential evapotranspiration $\left(E T_{p}\right)$ at Shanghai, shown in equation (1),

$$
E T_{p}=0.0023 R_{a}\left(T_{m}+17.8\right) \sqrt{T R}
$$

where $R_{a}$ is the extraterrestrial radiation, $T_{m}$ represents the daily mean air temperature and $T R$ is the temperature range between daily maximum and minimum air temperature. $R_{a}$ depends on the relative position between earth and sun and can be calculated as follows,

$$
R_{a}=\frac{G_{s c}}{\pi} d_{r}\left(w_{s} \sin \varphi \sin \delta+\cos \varphi \cos \delta \sin w_{s}\right)(2)
$$

where $G_{s c}=1360 \mathrm{~W} / \mathrm{m}^{2}$ is the solar constant, $\varphi, w_{s}, d_{r}$, and $\delta$ represent the site latitude, sunset hour angle, relative distance between earth and sun, and solar declination angle, respectively. As Shanghai is characterized by a subtropical monsoon climate, $E T_{p}$ is a good indicator of the evapotranspiration demand at Shanghai.

\subsection{Modeling subsurface flow transport}

In order to investigate the long term variability of groundwater dynamics at Shanghai, we developed a 1Dimensional model to simulate subsurface flow and transport using the Richard's equation, which is shown in equation (3),

$$
\frac{\partial \theta}{\partial t}=\frac{\partial}{\partial z}\left[-K(H)\left(\frac{\partial H}{\partial z}\right)\right]-R-E T
$$

where $\theta$ represents soil moisture, $K(H)$ is the hydraulic conductivity and $\mathrm{R}$ represents surface runoff. We used the modified Van Genuchten model [12-13] for the soil hydraulic parameters. We used a soil type of loam with parameters presented in table (1)., where $Q_{r}, Q_{s}, Q_{m}$, and $Q_{a}$ represent the residual soil water content, saturated water content, and parameters in the soil water retention function. $K_{k}$ represents the measured value of the hydraulic conductivity that corresponds to the soil moisture measure $Q_{k} . K_{s}$ is the saturated hydraulic conductivity. $\alpha$ and $n$ are paraemters used in the water retention function and $I$ is the tortuosity parameter. Other parameter values can be used if additional data becomes available.

\subsection{Sensitivity analysis and statistical analysis}

As climate change has a profound influences over earth system dynamics, lots of research have focused on quantifying how dynamic changes in temperature and precipitation patterns further result in variations in

Table 1. Soil hydraulic parameters

\begin{tabular}{rrrrrrrrrr}
\hline$Q_{r}$ & $Q_{s}$ & $\alpha$ & $n$ & $K s$ & $I$ & $Q_{m}$ & $Q_{a}$ & $Q_{k}$ & $K_{k}$ \\
\hline 0.078 & 0.43 & 0.036 & 1.56 & 24.96 & 0.5 & 0.43 & 0.078 & 0.43 & 24.96 \\
\hline
\end{tabular}

evapotranspiration and subsurface dynamics. In this study, we applied a simple sensitivity analysis with fluctuating minimum and maximum daily temperature, and precipitation to test how temperature and precipitation variations influence subsurface soil moisture as well as potential evapotranspiration at Shanghai. We also applied numerous statistical approaches, including regression and hypothesis tests to determine how subsurface soil moisture dynamics and potential evapotranspiration correspond to perturbations in air temperature and precipitation.

\section{Results and discussions}

In this section, we will present the main results in this study and discuss the implications from this study. Specifically, in section 3.1 we will walk through the current precipitation and air temperature pattern with the measured data at Shanghai. Section 3.2 presents the simulation results for potential evapotranspiration and soil moisture estimation and dynamics quantification are presented in section 3.3. Results from the sensitivity analysis are discussed in section 3.4 


\subsection{Precipitation and temperature pattern}

Significant temporal variability in precipitation and air temperature patterns were observed at Shanghai. Figure 1 presents the annual cumulative precipitation at Shanghai. We observed $30 \%$ more annual precipitation in a wetter year (e.g., 1999), which is almost twice as large as the driest year (e.g., 2003) comparing to normal years (e.g., 2012). In addition, the timing of precipitation inputs also

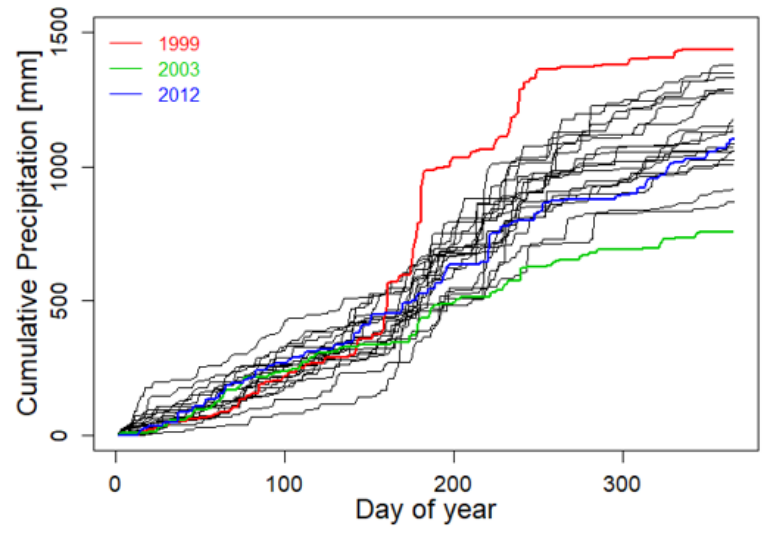

vary significantly across different years. Even if 1999 has significantly greater precipitation than 2003 and 2012, most of these additional precipitation occurred during monsoon seasons, whereas winter and spring precipitation inputs among these three divergent years remain very similar. The greater contribution from a relatively shorter period of time can increase environmental risks significantly, such as the occurrences of floods.

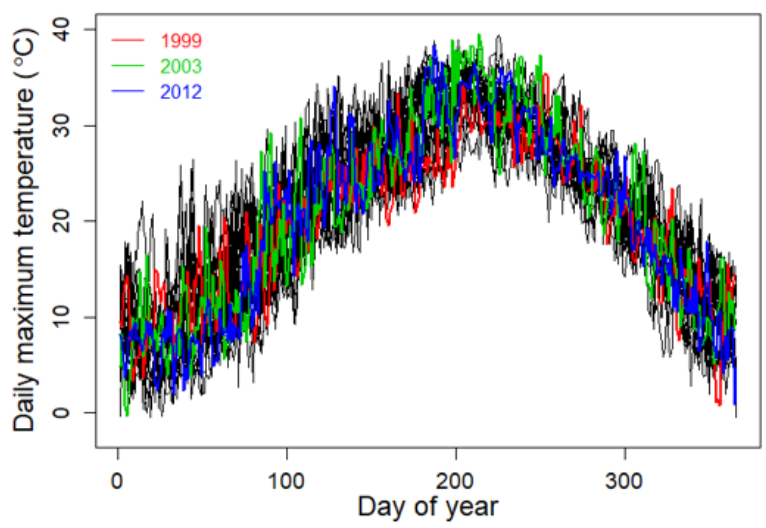

Figure 1. Cumulative precipitation and time series of maximum daily air temperature

Considering the time series of daily maximum air temperature. we observed very similar dynamics trends across different seasons among 1999, 2003 and 2012 regardless of the precipitation inputs. Air temperature at Shanghai ranges from a few degrees under the freezing point to over $40^{\circ} \mathrm{C}$ during hot summers. We have identified approximately 2 degree higher air temperature in winter spring seasons in 1999 compared to the other two years; and significantly smaller air temperature during monsoon periods. These significant temporal variability in temperature and precipitation patterns jointly contribute to the long-term temporal variability in ecosystem dynamics and hydrological responses.

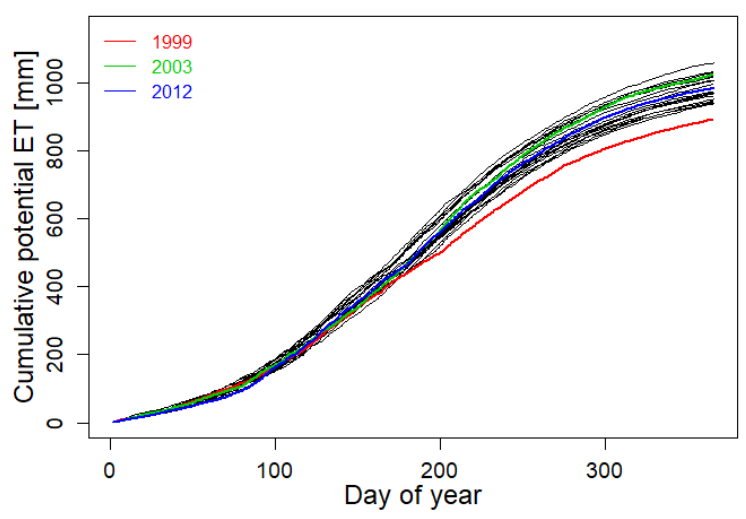

\subsection{Potential evapotranspiration at Shanghai}

Quantifying the temporal variability of potential evapotranspiration provides useful information for us to better quantify the hydrological responses to the varying climate. Figure 2 presents the simulated annual cumulative $E T_{p}$ and time series of $E T_{p}$ at Shanghai. For most of the years, we have observed a smaller annual $E T_{p}$ than annual cumulative precipitation, indicating that ecosystem in Shanghai is very likely to experience moisture limiting conditions. Unlike differences in precipitation among 1999, 2003 and 2012, we have observed opposite relationship in $E T_{p}$, where annual cumulative $E T_{p}$ is the smallest in 1999 compared to the other years. Considering the time series of $E T_{p}$, significant smaller $E T_{p}$ during summer monsoon seasons in 1999 is the major factor that led to different annual cumulative $E T_{p}$.

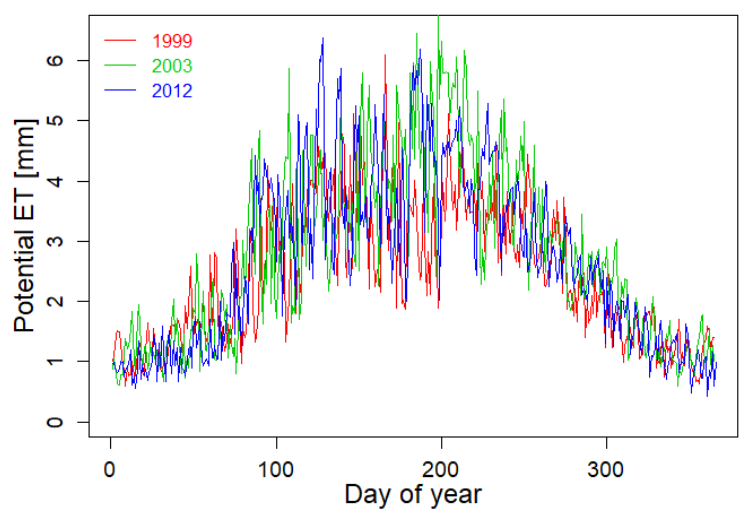

Figure 2. Annual cumulative potential evapotranspiration and time series of potential evapotranspiration at Shanghai 
High correlation between annual mean air temperature and $E T_{p}$ was observed, whereas a negative correlation between daily mean precipitation and $E T_{p}$ was identified. Higher air temperature is usually related with greater radiation inputs, which increases the evapotranspirative demands at Shanghai, whereas longer periods of precipitation events during monsoon season usually

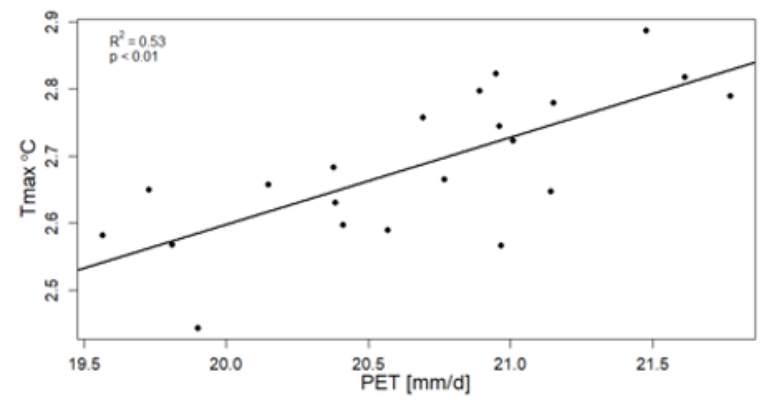

coincide with greater cloud cover that reflects radiation and further decrease temperature. Thus we observed a weak negative correlation between daily precipitation inputs and $E T_{p}$. As Shanghai receives ambient precipitation inputs, it is very likely that actual ET is mainly constrained by energy related factors.

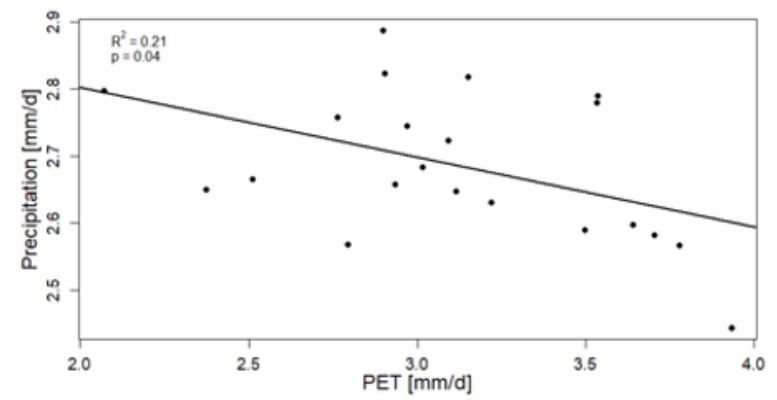

Figure 3. Linear regression among potential evapotranspiration and annual mean temperature and annual mean precipitation

\subsection{Estimation of soil moisture dynamics at Shanghai}

We selected four depths to quantify the soil moisture dynamics at this Shanghai site. Figure 4 presents the monthly-based temporal variability of soil moisture at 10 , 30,50 and $70 \mathrm{~cm}$, respectively. In general, we have observed significantly greater temporal variability of soil moisture at shallower locations compared to deeper soil. For example, in winter and spring periods where

\section{Soil moisture at $10 \mathrm{~cm}$}

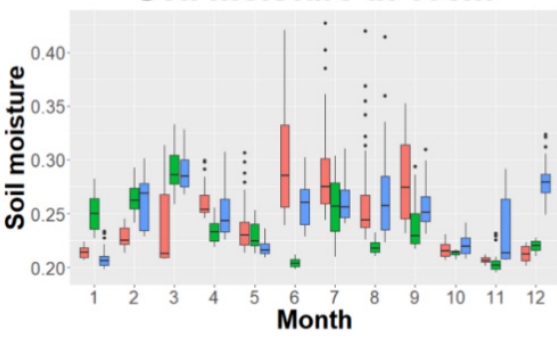

Soil moisture at $50 \mathrm{~cm}$

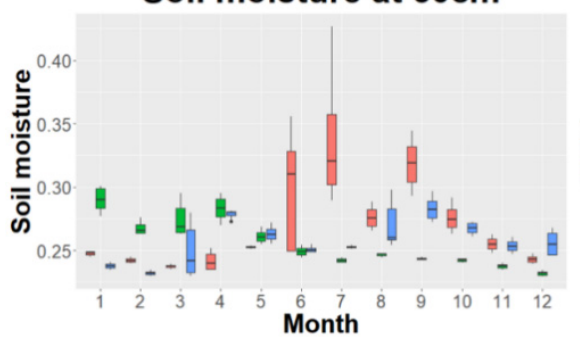

precipitation inputs at Shanghai stay relatively small, we do not observe larger variability among 1999, 2003 and 2012. However, during peak rainfall seasons (e.g., June and July), we have observed large variability in soil moisture even at $70-\mathrm{cm}$ deep, which indicates the greater infiltration and drying due to evapotranspiration when there was no rain events. In normal or dry years, monsoon precipitation is effective for shallower subsurface, however these rain precipitation cannot penetrate to the deeper subsurface, where we observe almost no temporal variability during monsoon season in 2003 and 2012.

\section{Soil moisture at $30 \mathrm{~cm}$}

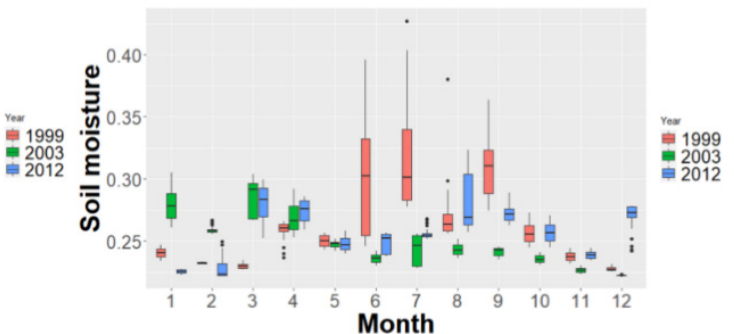

Soil moisture at $70 \mathrm{~cm}$

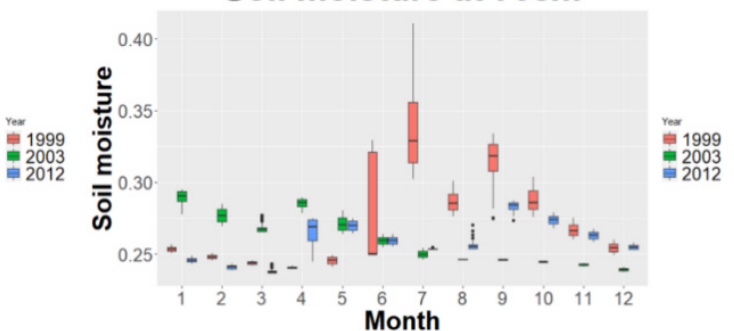

Figure 4. Temporal variability of soil moisture at 10,30,50 and $70 \mathrm{~cm}$ at the Shanghai site

Magnitude and timing of precipitation puts are the major contributing factors that drive soil moisture dynamics in the subsurface. Figure 5 presents the statistical correlation between soil moisture at different depths versus daily temperature and precipitation inputs. For all pairs between temperature and moisture, there is no statistical significant correlation in between. Whereas, we observe a positive correlation between precipitation inputs and soil moisture in the subsurface at all depths. These results indicate that increase and decreases in the availability of precipitation components will have a profound influence over soil moisture dynamics in the subsurface. 

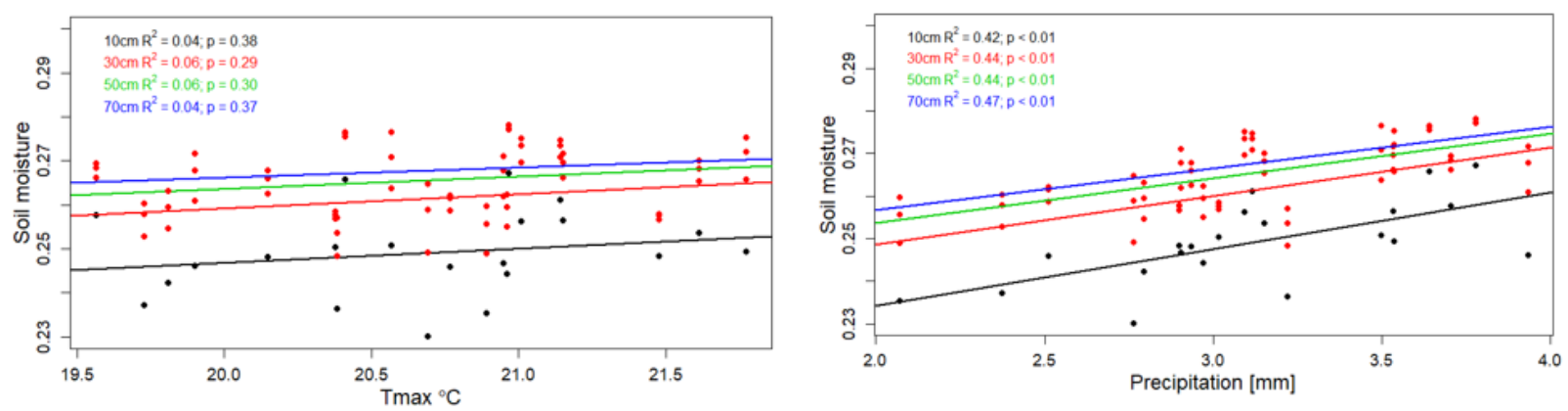

Figure 5. Regression among temperature versus soil moisture and precipitation versus soil moisture

\subsection{Sensitivity analysis}

Understanding the dynamics of soil moisture and potential evapotranspiration under climate change is important to improve our energy, water and resources management. In this section, we presented how changes in temperature influences potential evapotranspiration and perturbations in precipitation inputs control soil moisture dynamics.

Perturbations in precipitation have a tremendous impact over soil moisture dynamics at all depths. For

\section{Soil moisture at $10 \mathrm{~cm}$}

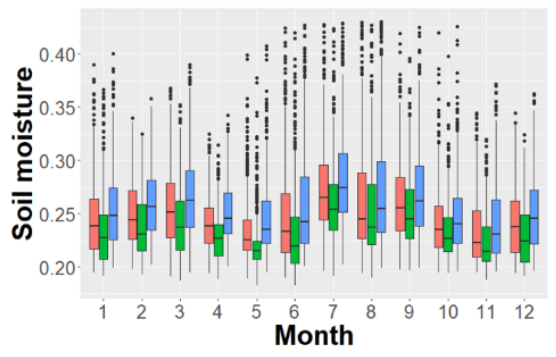

Soil moisture at $50 \mathrm{~cm}$

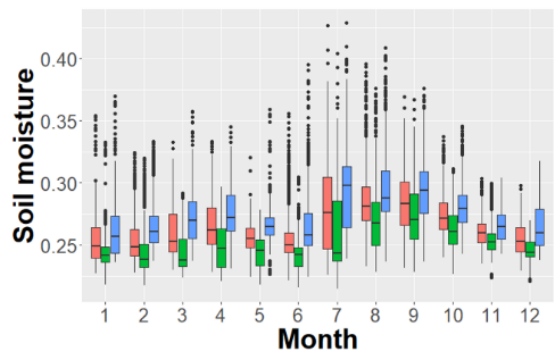

example, considering shallow subsurface during May, we observe more than $50 \%$ greater soil moisture when precipitation is $20 \%$ higher than current compared to smaller precipitation inputs. This differences became more exaggerated when we compared July soil moisture at $50 \mathrm{~cm}$. The long-term mean of soil moisture for undisturbed is around 0.28 , compare to 0.25 and 0.31 when we hypothesize a $20 \%$ change in precipitation inputs. These results are visualized in figure 6.

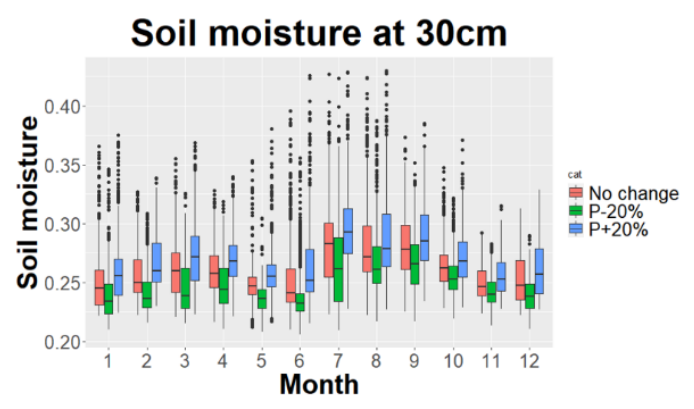

Soil moisture at $70 \mathrm{~cm}$
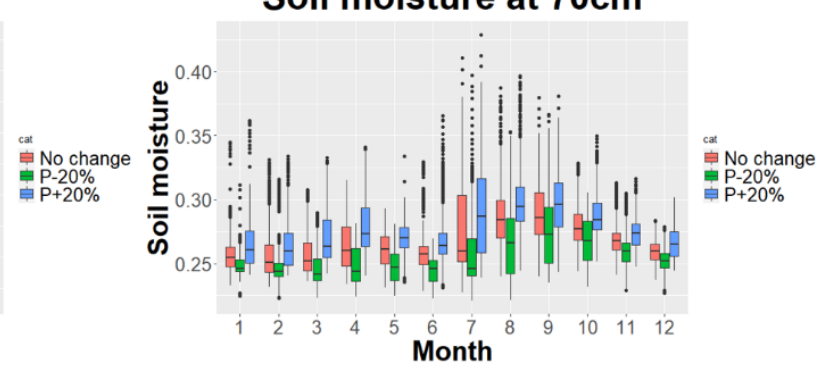

Figure 6. Soil moisture's sensitivity to precipitation variation.

In addition, we also tested how variations in daily maximum and minimum temperature controls potential evapotranspiration. Figure 7 displays the daily mean potential ET over the 4 perturbated groups compared to the original situation. We could observe the greatest changes when maximum temperature increases or decrease by $2^{\circ} \mathrm{C}$. On an annual cycle, this will lead to approximately $\sim 150 \mathrm{~mm} / \mathrm{yr}$ in $E T_{p}$ differences. On the other hand, reducing minimum temperature by $2^{\circ} \mathrm{C}$ have a similar influence over $E T_{p}$ compared to increasing maximum temperature. However, there's also most no statistical differences when we increase daily minimum temperature by $2^{\circ} \mathrm{C}$ with all other factors constant. Though these results are hypothesized with a 2 degree fluctuation around the original datasets, these results still indicate changing climate will have a profound influence over potential evapotranspiration and soil moisture given recent findings of global scale increases in temperature and more randomness in precipitation patterns [14]. 


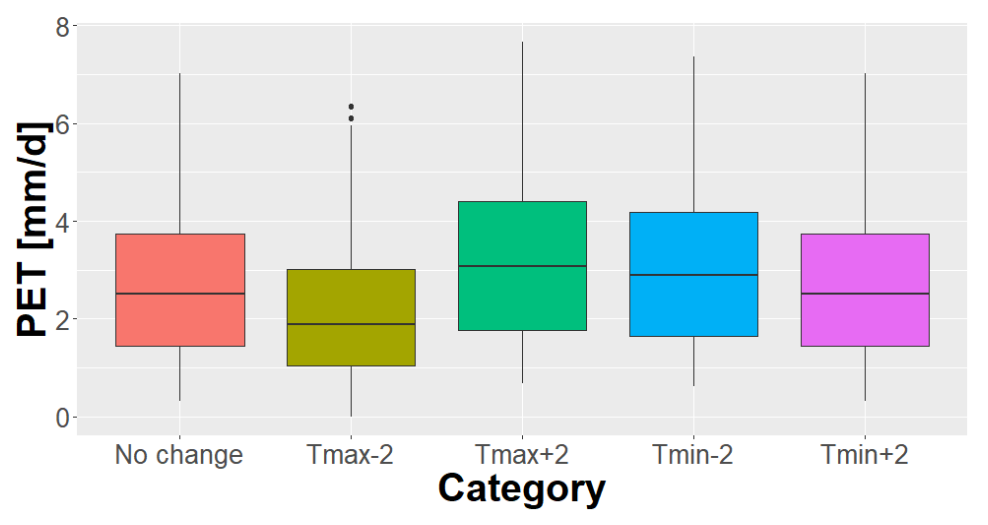

Figure 7. Potential evapotranspiration's sensitivity to temperature variation

\section{Conclusions}

In this study, we focused on providing a process-based estimate of potential evapotranspiration and soil moisture dynamics in the subsurface for Shanghai due to its socioeconomic significance. Statistical analysis indicated significant inter-annual variability in temperature and precipitation patterns at Shanghai, where annual precipitation in 1999 is almost twice the amount of precipitation for 2003. We also observed a significant smaller air temperature during summer monsoon season in 1999 compared to 2003 and 2012. These heterogeneous factors in meteorological conditions further result in significant temporal variability in potential evapotranspiration and soil moisture.

Our estimation utilized the Hargreaves equation, which only requires precipitation and air temperature data to estimate potential evapotranspiration. 1-D subsurface flow transport was used to simulate soil moisture dynamics at Shanghai. Our results showed significant differences in annual cumulative potential evapotranspiration. Where we observed the smallest cumulative $E T_{p}$ in 1999 compared to other years, which corresponds to the decreasing temperature during summer monsoon season. Our results further indicated larger variability in the soil moisture of shallower subsurface compared to deeper soils, where only in 1999 we observed larger variability during June and July periods. A high correlation between temperature and potential evapotranspiration was observed and a high correlation between precipitation inputs and the subsurface soil moisture was identified. These results helped us to distinguish how temperature and precipitation patterns arise temporal variability in potential evapotranspiration and soil moisture.

We also tested how soil moisture and potential evapotranspiration respond to perturbations in daily minimum and maximum temperature and precipitation inputs. Our results indicate that potential evapotranspiration will change significantly when daily maximum temperature increases by $2^{\circ} \mathrm{C}$ or daily minimum temperature decreases by $2^{\circ} \mathrm{C}$. With increasing daily contrast in temperature, potential evapotranspiration will increase. In addition, changes in precipitation have a profound effects on soil moisture dynamics. For example, shallow soil moisture will decrease by almost $40 \%$ with only $20 \%$ decreases in precipitation inputs. Even though researchers and scientists have not distinguished the unique role of climate change on ecosystem dynamics, our sensitivity analysis indicated a small change in climate meteorological forcing conditions can have a dramatic influence over soil moisture and potential evapotranspiration at Shanghai.

We want to acknowledge that the use of soil type and parameter values should not restrict the conclusions presented in this study. We believe other more complicated models can be more effective in identifying how climate change and urbanization controls ecosystem dynamics when measured data become readily available. Original dataset used in this study can be accessed from the Shanghai Meteorological Bureau website and simulation results are available upon request.

\section{Acknowledgement}

We greatly appreciate all the help and guidance received from ViaX education. Collaborations and classes through ViaX education significantly advanced our knowledge.

\section{Reference}

1. Zhang, Y., Chiew, F. H. S., Peña-Arancibia, J., Sun, F., Li, H. and Leuning, R.: Global variation of transpiration and soil evaporation and the role of their major climate drivers, J. Geophys. Res. (2017), doi:10.1002/2017JD027025

2. Knowles, J. F., Burns, S. P., Blanken, P. D. and Monson, R. K.: Fluxes of energy, water, and carbon dioxide from mountain ecosystems at Niwot Ridge, Colorado, Plant Ecol. Divers. (2015), doi:10.1080/17550874.2014.904950

3. Levine, J. B. and Salvucci, G. D.: Equilibrium analysis of groundwater-vadose zone interactions and the resulting spatial distribution of hydrologic fluxes across a Canadian prairie, Water Resour. Res., 35, 5 (1999), 1369-1383, doi:10.1029/1999WR900018

4. Rumsey, C. A., Miller, M. P., Susong, D. D., Tillman, F. D. and Anning, D. W.: Regional scale estimates of 
baseflow and factors influencing baseflow in the Upper Colorado River Basin, J. Hydrol. Reg. Stud., 4, PB (2015) 91-107, doi:10.1016/j.ejrh.2015.04.008

5. Qiu, G. yu, LI, H. yong, ZHANG, Q. tao, CHEN, W., LIANG, $X$. jian and LI, X. ze: Effects of Evapotranspiration on Mitigation of Urban Temperature by Vegetation and Urban Agriculture, J. Integr. Agric. (2013) doi:10.1016/S20953119(13)60543-2

6. Taha, H.: Urban climates and heat islands: Albedo, evapotranspiration, and anthropogenic heat, Energy Build.(1997) doi:10.1016/s0378-7788(96)00999-1

7. Basu, B. and Srinivas, V. V.: Regional flood frequency analysis using kernel-based fuzzy clustering approach, Water Resour. Res., 50, 4 (2014) 3295-3316, doi:10.1002/2012WR012828

8. Hargrove, W. W., Hoffman, F. M. and Law, B. E.: New analysis reveals representativeness of the amerflux network, Eos (Washington. DC)., 84, 48 (2003) doi:10.1029/2003EO480001

9. Zou, Z., Yang, Y. and Qiu, G. Y.: Quantifying the evapotranspiration rate and its cooling effects of urban hedges based on three-temperature model and infrared remote sensing, Remote Sens. (2019) doi:10.3390/rs11020202

10. Ma, N., Zhang, Y., Xu, C. Y. and Szilagyi, J.: Modeling actual evapotranspiration with routine meteorological variables in the data-scarce region of the Tibetan Plateau: Comparisons and implications, J. Geophys. Res. G Biogeosciences (2015) doi:10.1002/2015JG003006

11. Jensen, D. T., Hargreaves, G. H., Temesgen, B. and Allen, R. G.: Computation of ETo under nonideal conditions, J. Irrig. Drain. Eng. (1997), doi:10.1061/(ASCE)0733-9437(1997)123:5(394)

12. van Genuchten, M. T.: A Closed-form Equation for Predicting the Hydraulic Conductivity of Unsaturated Soils, Soil Sci. Soc. Am. J. (1980) doi:10.2136/sssaj1980.03615995004400050002x

13. Vogel, T. and Cislerova, M.: On the reliability of unsaturated hydraulic conductivity calculated from the moisture retention curve, Transp. Porous Media (1988) doi:10.1007/BF00222683

14. IPCC: IPCC 2019- Special report on climate change, desertification, land degradation, sustainable land management, food security, and greenhouse gas fluxes in terrestrial ecosystem, Res. Handb. Clim. Chang. Agric. Law (2019), doi: $10.4337 / 9781784710644$ 